\title{
Investigator Identifier
}

National Cancer Institute

\section{Source}

National Cancer Institute. Investigator Identifier. NCI Thesaurus. Code C83078.

A sequence of characters used to identify, name, or characterize the study investigator. 